\section{Scion Inclination in Malus domestica Borkh. and Prunus spp. Influences Root Growth and Distribution}

\author{
Giorgio Bargioni and Giorgio Baroni \\ Institute for Fruit Growing of the Province of Verona, 37100 Verona, Italy \\ Pietro Tonutti, Andrea Pitacco, and Angelo Ramina \\ Institute of Pomology, University of Padova, 35100 Padova, Italy
}

Additional index words. apple, peach rootstock INRA GF 677, root $\times$ shoot interaction

\begin{abstract}
Effects of scion inclination on root growth and distribution were studied on INRA GF 677 (Prunus persica $x$ Prunus amygdalus) and apple/M.9 trees. At planting, central leaders were positioned vertically $\left(0^{\circ}\right)$ or inclined $45^{\circ}$ or $60^{\circ}$ to the north and south. Three years after planting, root total dry weight of inclined trees was lower than that of the control $\left(0^{\circ}\right.$, vertical central leader $)$. Five years after planting, the isotropic distribution of the normal root systems was distorted by inclination in both species. Roots were more numerous and more elongated in the direction of inclination. Statistical analysis of root density data, using a polar coordinate system, confirmed that the trunk inclination reduced root development and redirected root distribution. The major effect was induced on GF 677 by $60^{\circ}$ inclinations. Tree orientation did not seem to influence root distribution.
\end{abstract}

Root distribution of fruit trees is controlled genetically and environmentally. Under nonlimiting conditions and in a uniform soil the root system spreads radially from the trunk, penetrating the available soil volume. Among factors affecting root growth and distribution, those concerning the mutual root $\times$ shoot interaction are numerous and responsible for achieving a constant root: shoot ratio. This coordination results from a functional equilibrium between these two plant parts (Brouwer, 1983; Lambers, 1983). Root and shoot activities may be coordinated by two bidirectional messenger currents, in which plant hormones may play a pivotal role (Lockard and Schneider, 1981; Russell, 1977).

Physical or chemical manipulations of the crown or roots have mutual effects in terms of physiology and morphology, which is relevant to fruit tree production where certain training systems that modify the natural shape of the canopy also may affect root distribution. Modifying branch or central leader angles as a means of controlling vigor is common in fruit tree training. Although the effects of these operations on the canopy are well described, information about influences on root morphogenesis is lacking. To our knowledge, few reports exist in this field: Nicotra (1967) and Ponomarchuk and Golovanov (1973) found that apple and peach trees, trained to palmette, had a radial root system. Studying different peach training systems, Dziljanov (1965)found a relation, in terms of shape, between canopy

Received for publication 18 July 1994 . Accepted for publication 9 Jan. 1995. Authorized for publication as paper no. 295 of the scientific journal series of the Institute of Pomology, Univ. of Padova, Padova, Italy. The cost of publishing this paper was defrayed in part by the payment of page charges. Under postal regulations, this paper therefore must be hereby marked advertisement solely to indicate this fact. and root development. Because inclination changes the hormone distribution within the branches, dramatically affecting budbreak and shoot elongation, from a physiological point of view, it is reasonable to expect that treatments that so strongly influence canopy morphogenesis also may modify the orientation of root growth and development.

\section{Materials and Methods}

Plant material. To evaluate the effect of scion inclination on root orientation and distribution, 1-year-old seedlings of INRA GF 677 (Prunus persica $\times$ Prunus amygdalus) and expressed as average annual growth. apple trees ('Golden Delicious'/M.9) were transplanted at the farm of the Experimental Institute for Fruit Growing of the Province of Verona, Ponton, Italy, in Spring 1988. The lime-sand soil, which originated from sediments of the Adige River, was 50 to $60 \mathrm{~cm}$ deep and homogeneous in composition and structure. The experimental field had a slight slope $(0.3 \%)$ westward. Before planting, the soil was ploughed to a depth of $40 \mathrm{~cm}$ and harrowed.

Trees were planted in north-south-oriented rows with $3.0 \mathrm{~m}$ apart within and between rows. At planting, the tree central leaders were positioned as follows: $0^{\circ}$ (control), $45^{\circ}$ north, $45^{\circ}$ south, $60^{\circ}$ north, and $60^{\circ}$ south from the vertical. The position of the central leaders was maintained throughout the experiment using stakes.

Each treatment was performed on three randomized blocks of three trees each. Vertical trees were trained to the palmetta and inclined trees to the drapeau Marchand systems. In the latter system, the trunk is inclined $\left(30^{\circ}\right.$ to $\left.45^{\circ}\right)$ and the branches are trained to the side opposite that of the trunk inclination (Gautier, 1969). A herbicide-treated strip was maintained within rows, with grass sod between rows. Summertime overhead-sprinkler irrigation was used. At the end of each growing season, trunk circumference and central leader elongation were measured. Trees were pruned in the winter to maintain trees in the assigned form and to equilibrate growth.

Three years after planting, in one block each of GF 677 and apple per treatment, the above-ground parts of the trees were removed and the roots were dug out using a water jet. The root system was divided in two sectors (north and south) using a virtual plane centered on the trunk stump and east-west oriented. Dry weight of roots present in the two sectors was determined.

Table 1. Effect of trunk inclination in INRA GF 677 (Prunus) and apple ('Golden Delicious'/M.9) on trunk circumference, measured at the end of the third year after planting, and central leader elongation,

\begin{tabular}{lccccc}
\hline \hline & \multicolumn{2}{c}{ INRA GF 677 } & & \multicolumn{2}{c}{ Apple } \\
\cline { 2 - 3 } \cline { 5 - 6 } & $\begin{array}{c}\text { Trunk } \\
\text { circumference } \\
(\mathrm{cm})^{\mathrm{z}}\end{array}$ & $\begin{array}{c}\text { Central } \\
\text { leader elongation } \\
(\mathrm{cm} / \text { /year })^{\mathrm{z}}\end{array}$ & & $\begin{array}{c}\text { Trunk } \\
\text { circumference } \\
(\mathrm{cm})^{\mathrm{z}}\end{array}$ & $\begin{array}{c}\text { Central } \\
\text { leader elongation } \\
(\mathrm{cm} / \text { year })^{\mathrm{z}}\end{array}$ \\
\hline $45^{\circ} \mathrm{N}$ & $26.0 \mathrm{a}$ & $90.1 \mathrm{a}$ & & $11.9 \mathrm{~b}$ & $34.8 \mathrm{~b}$ \\
$45^{\circ} \mathrm{S}$ & $24.4 \mathrm{a}$ & $81.2 \mathrm{a}$ & & $11.8 \mathrm{~b}$ & $39.9 \mathrm{~b}$ \\
$60^{\circ} \mathrm{N}$ & $22.1 \mathrm{~b}$ & $77.9 \mathrm{a}$ & & $10.5 \mathrm{c}$ & $35.7 \mathrm{~b}$ \\
$60^{\circ} \mathrm{S}$ & $20.5 \mathrm{c}$ & $71.2 \mathrm{a}$ & & $10.6 \mathrm{c}$ & $31.3 \mathrm{~b}$ \\
$0^{\circ}$ (control) & $27.7 \mathrm{a}$ & $92.7 \mathrm{a}$ & & $14.2 \mathrm{a}$ & $55.6 \mathrm{a}$ \\
\hline
\end{tabular}

${ }^{2}$ Values are means of nine trees. Mean separation in columns by Duncan's multiple range test at $P \leq 0.05$.

Table 2. Effect of trunk inclination on root dry weight in INRA GF 677 (Prunus) and apple ('Golden Delicious'/M.9) trees. Three years after planting, root dry weight was measured separately in the north and south sectors, defined by a virtual plane centered on the trunk stump and east-west oriented.

\begin{tabular}{|c|c|c|c|c|c|c|}
\hline \multirow[b]{3}{*}{ Inclination } & \multicolumn{6}{|c|}{ Root dry wt (g) } \\
\hline & \multicolumn{3}{|c|}{ INRA GF 677} & \multicolumn{3}{|c|}{ Apple } \\
\hline & North sector & South sector & Total $^{\mathrm{z}}$ & North sector & South sector & Total $^{2}$ \\
\hline $45^{\circ} \mathrm{N}$ & 1808 & 1778 & $3586 \mathrm{ab}$ & 144 & 65 & $209 \mathrm{c}$ \\
\hline $45^{\circ} \mathrm{S}$ & 1043 & 2156 & $3199 \mathrm{~b}$ & 127 & 229 & $356 \mathrm{~b}$ \\
\hline $60^{\circ} \mathrm{N}$ & 571 & 492 & $1063 \mathrm{c}$ & 249 & 81 & $330 \mathrm{~b}$ \\
\hline $60^{\circ} \mathrm{S}$ & 907 & 2541 & $3448 \mathrm{~b}$ & 84 & 283 & $367 \mathrm{~b}$ \\
\hline $0^{\circ}$ (control) & 1776 & 1833 & $3609 a$ & 209 & 188 & $397 \mathrm{a}$ \\
\hline
\end{tabular}

${ }^{2}$ Mean separation in columns by Duncan's multiple range test at $P \leq 0.05$. 
Five years after planting, roots of all the remaining trees were dug out using the same procedure. A $0.5 \times 0.5-\mathrm{m}$, square grid was centered on the tree stump, and total length of roots $>3 \mathrm{~mm}$ in diameter was recorded in each square to estimate the local root density (centimeter per square meter). The entire root system of each tree was graphically represented as a horizontal projection.

Statistics. To have the most straightforward test of the treatment effect on the spatial distribution of the roots, all measurements were referred to a polar coordinate system, based on the distance from the tree stump $(d)$ and the absolute value of the angle $(\alpha)$, assuming the horizontal projection of each tree trunk as the reference axis for determining $\alpha$ value. For a perfect isotropic root system, this component would not result in statistically significant differences. A source of variation due to the ground slope also was included.

Data were statistically analyzed using a least-squares analysis of variance approach, where treatments (inclination) and orientation were considered main effects, and $d$ and $\alpha$ continuous variables. Two-way interactions of both independent variables with the treatment effect also were tested. Treatment means and the significance of their differences were computed by estimating linear functions of the effects and contrasts.

Patterns of root system distribution were obtained after Kriging was applied to the original points. This technique, borrowed from the branch of statistics related to the analysis of spatial data (geostatistics), can provide optimal estimates of regionalized variables at unsampled locations (Trangmar et al., 1985). Estimates are weighted averages of the observed values at the gridpoints between sampled points, calculated based on a known autocorrelation pattern in one or more dimension of the space. Empty squares were discarded in statistical analysis and contouring.

\section{Results}

As expected, trunk inclination negatively affected growth of the upper part of the trees (Table 1). By 3 years after planting, $60^{\circ}$ inclination reduced trunk circumference in GF 677 (Prunus) and apple. Following inclination, the average growth of the central leader was reduced significantly in apple but not in GF 677 .

Data collected 3 years after planting showed that inclination reduced the root total dry matter, with the exception of GF 677 inclined $45^{\circ}$ north (Table 2). Treatments significantly affected root dry matter distribution, with higher values in sectors located in the direction of inclination.

Morphological observations revealed that, regardless of treatment, the root system of GF 677 and apple was confined within the top 40 $\mathrm{cm}$ of soil. In trees with a vertical central leader, roots spread from the base of the trunk more or less in all directions, although genetic differences emerged between GF 677 and apple. In the latter, roots colonized a smaller soil volume and were less numerous and more elongated. A preferential development of roots toward the direction of inclination occurred in GF 677 (Fig. 1, right) and apple. This behavior was confirmed 5 years after planting. Generally, roots opposite the direction of inclination were less numerous and elongated; those that developed toward the interrow space were initially straight then curved, and they continued to elongate in the direction of inclination.

The distribution of the contour lines, which encircled areas with the same root density, displayed an isotropic gradient in trees with a vertical central leader (Fig. 2A). Central leader inclination caused a marked displacement of the contour lines toward the direction of inclination in apple and GF 677 (Fig. 2 B and C). Contour lines were similar for $45^{\circ}$ and $60^{\circ}$ inclination in apple, but in GF 677, major modifications were induced only by a $60^{\circ}$ inclination. Compared to the control, all the inclined GF 677 trees, except those with a $60^{\circ}$ south inclination, had a lower root density in the area adjacent to the trunk. The opposite was found in apple (Fig. 2).

Statistical analysis indicated that all changes from vertical produced highly significant effects on root density, although some differences emerged between GF 677 and apple. For GF 677, linear and quadratic components of the regression for $d$ but only the linear component for $\alpha$ were significant (Table 3 ). The treatment $\times d$ interaction was significant only for the linear component, whereas both components were significant in the treatment $\times \alpha$ interaction. In apple, both components of the regression for $d$ and only the linear component of the regression for $\alpha$ were significant (Table $3)$. Only the linear component of the treatment $\times \alpha$ was significant. For root density of GF 677 , the major effect was in the inclination of $60^{\circ}$ north and south (Table 4). Differences between $45^{\circ}$ and $60^{\circ}$ were significant in GF 677 but not in apple. No significant differences were detected in the orientation effect,

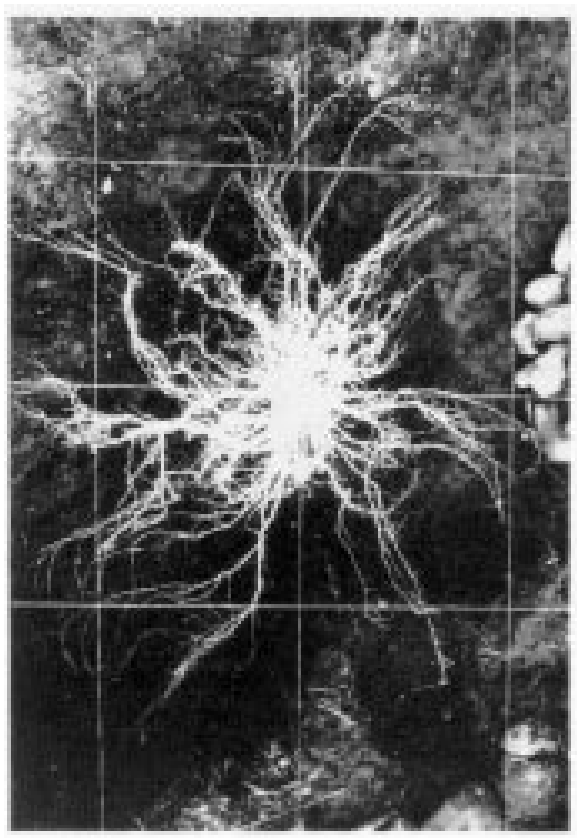

Fig. 1. Three-year-old root systems of (left) control (vertical central leader) and (right) inclined $\left(60^{\circ}\right.$ south) INRA GF 677 trees.

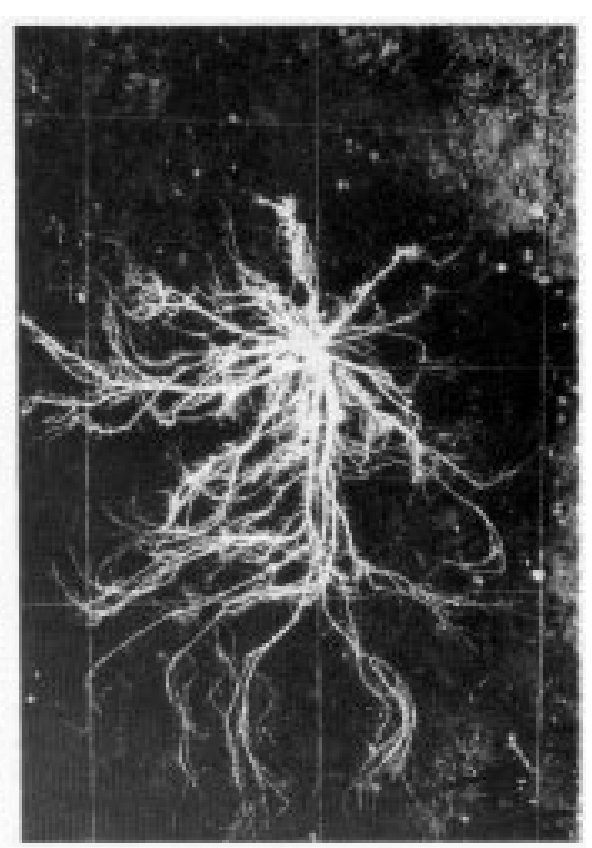

with the exception of apple inclined at $45^{\circ}$. The slight slope of the field to the west side significantly stimulated root growth toward the opposite direction. Despite this undesired source of variation, the effect of inclination remained significant (Table 4).

\section{Discussion}

Results demonstrate that the inclination of the central leader affects root growth and distribution. Three years after planting, the root total dry matter was generally lower in inclined trees, with a higher partition toward the side of inclination.

At the end of the experiment ( 5 years after planting), morphological observations confirmed the data and furnished detailed information on root distribution pattern. The most significant result is the distortion of the isotropic distribution of the root system induced by changing the trunk from the vertical position patterns. There is a clear tendency for roots to be more numerous and to elongate more in the direction of inclination. These results agree with Bargioni's (1993) observations on root systems of 23-year-old apple trees ('Golden Delicious'/M.7) trained to the drapeau Marchand system.

Of practical value when specific training systems are adopted, this information is also of physiological interest. The hypothesis that the modification of the root distribution, induced by inclining the central leader, is a morphological adjustment to better anchor the tree is ruled out by the similar results that we obtained on peach seedlings grown in hydroponic solution. These experiments started when plantlets had two fully expanded leaves and ran for 2 weeks, revealing that inclination of the stem caused a higher development of the root system on the side of inclination (data not shown). 
INRA GF 677

Control

A

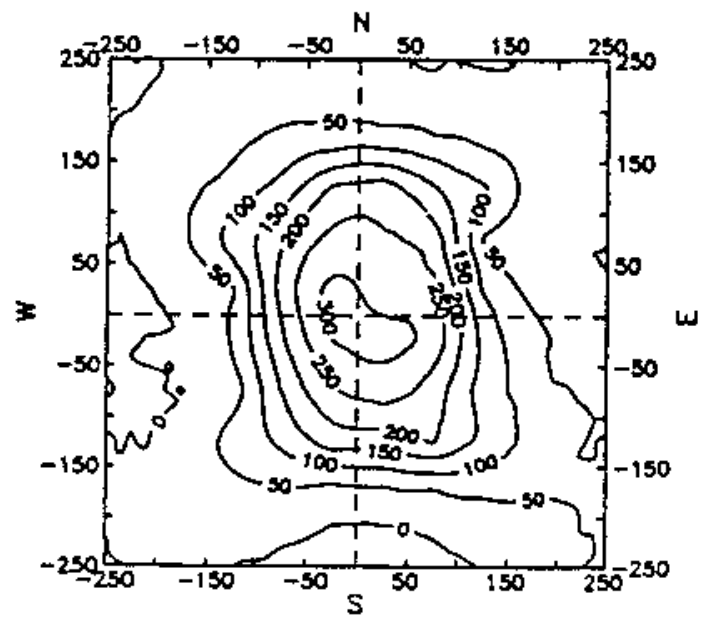

$60 \mathrm{~N}$

B

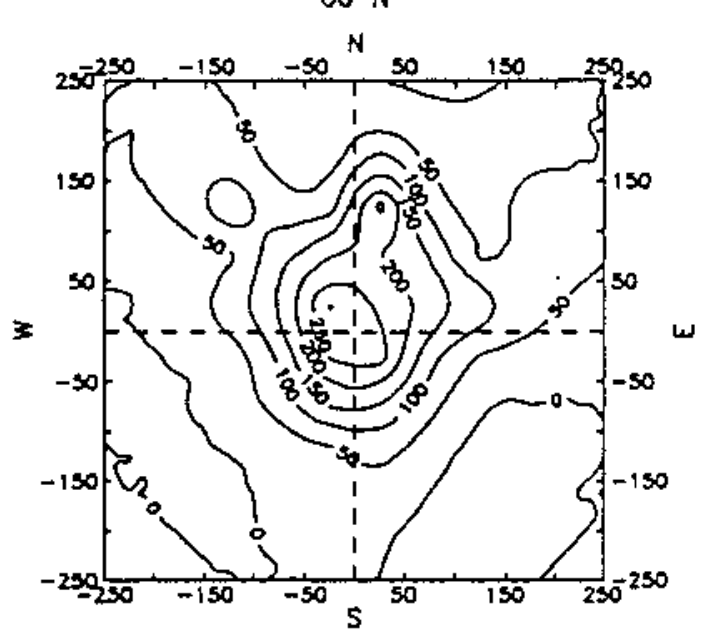

605

$\mathrm{C}$

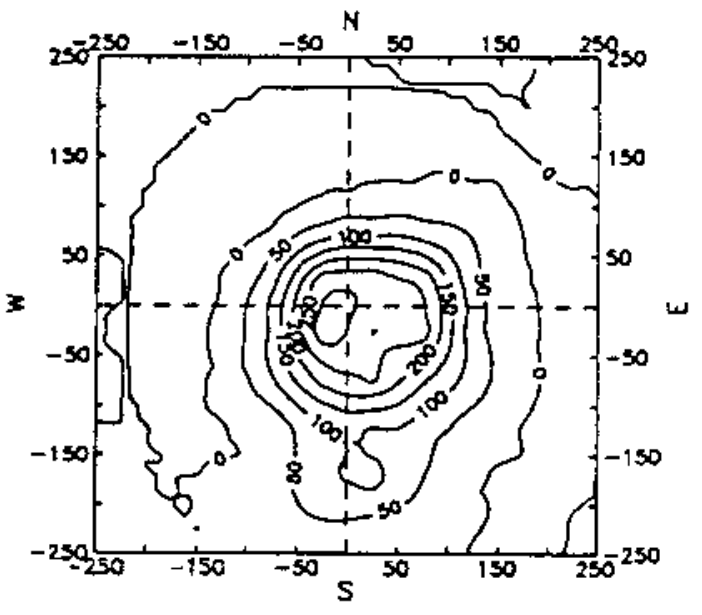

APPLE
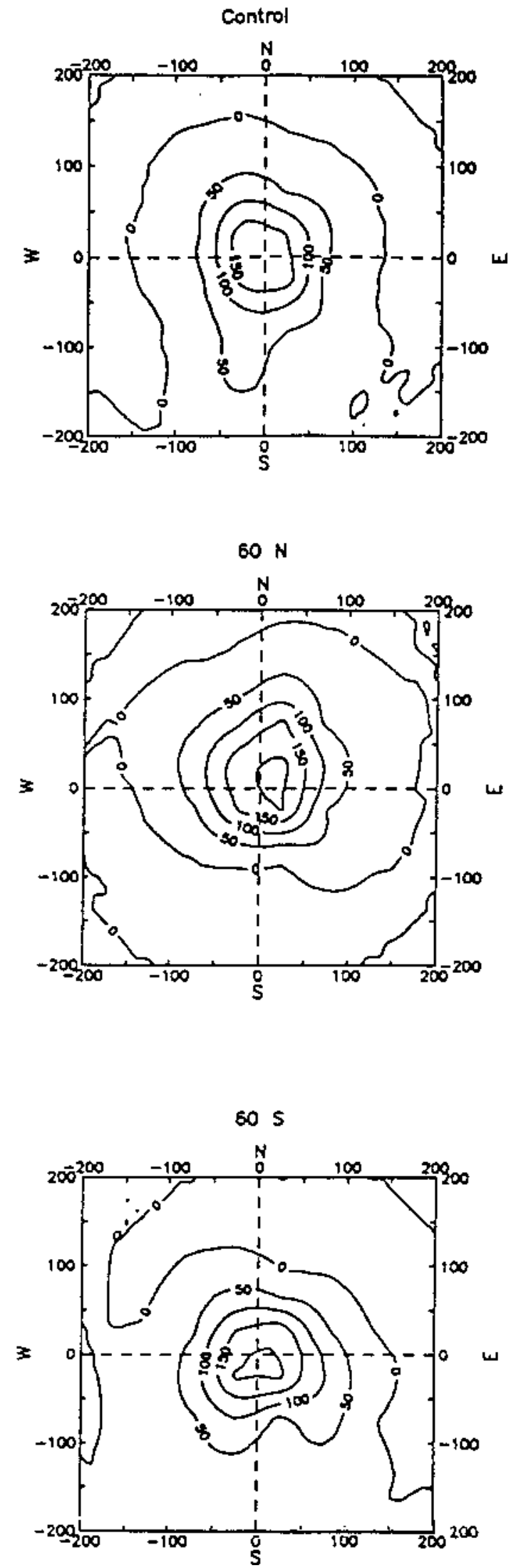

Fig. 2. Contour line distribution in the soil penetrated by (left) INRA GF 677 and (right) apple ('Golden Delicious'/M.9) roots 5 years after planting. Throughout the experiment, tree central leaders were positioned (A) vertically (control) or inclined at $(\mathbf{B}) 60^{\circ}$ north or $(\mathbf{C}) 60^{\circ}$ south. Contour lines define areas characterized by the same root density (centimeter per square meter) evaluated in a $0.5 \times 0.5-\mathrm{m}$, square grid system. 
The morphogenetic effect of inclining the central leader cannot merely be explained in terms of physiological homeostasis responsible for a metabolic coordination between plant parts (Klepper, 1991). A new concept of mass-distribution homeostasis, leading to a spatially balanced interrelated growth between shoot and root, should be considered. Accord-

Table 3. Least-squares analysis of variance for INRA GF 677 (Prunus) and apple ('Golden Delicious'/ M.9) root density.

\begin{tabular}{|c|c|c|c|c|c|c|c|}
\hline \multirow{4}{*}{ 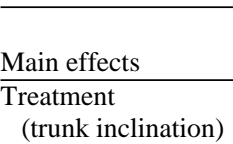 } & \multicolumn{2}{|c|}{ Probability } & \multirow{2}{*}{\multicolumn{5}{|c|}{$\begin{array}{l}\text { value of the angle, assuming the horizontal } \\
\text { projection of the trunk as reference axis. }\end{array}$}} \\
\hline & \multirow{2}{*}{ INRA GF 677} & \multirow{2}{*}{ Apple } & & & & & \\
\hline & & & & \multicolumn{2}{|c|}{ INRA GF 677} & \multicolumn{2}{|c|}{ Apple } \\
\hline & 0.0003 & 0.0021 & & Length & & Length & \\
\hline Ground slope & 0.0033 & 0.0142 & Variable & $(\mathrm{cm})$ & $\mathrm{SE}$ & $(\mathrm{cm})$ & $\mathrm{SE}$ \\
\hline \multicolumn{3}{|c|}{ Regression and interactions } & $\overline{45^{\circ} \mathrm{N}}$ & 27.72 & 2.09 & 15.14 & 2.62 \\
\hline Distance $(d)$ & & & $45^{\circ} \mathrm{S}$ & 27.89 & 2.17 & 22.61 & 2.30 \\
\hline Linear & 0.0000 & 0.0000 & $60^{\circ} \mathrm{N}$ & 19.75 & 2.48 & 16.66 & 2.40 \\
\hline Quadratic & 0.0000 & 0.0000 & $60^{\circ} \mathrm{S}$ & 20.68 & 3.19 & 16.99 & 2.72 \\
\hline \multirow{2}{*}{$\begin{array}{l}\text { Treatment } \times \\
d \text { linear }\end{array}$} & & & $0^{\circ}$ (control) & 36.67 & 3.14 & 9.03 & 2.33 \\
\hline & 0.0055 & 0.1154 & Slope (west side) & 24.65 & 1.41 & 14.55 & 1.29 \\
\hline \multirow{2}{*}{$\begin{array}{r}\text { Treatment } \times \\
d \text { quadratic }\end{array}$} & & & Slope (east side) & 28.43 & 1.29 & 17.63 & 1.25 \\
\hline & 0.1374 & 0.2656 & Contrast $(P>\mathrm{F})$ & \multirow{2}{*}{\multicolumn{2}{|c|}{0.000}} & & \\
\hline \multicolumn{3}{|l|}{ Angle $(\alpha)^{2}$} & $0^{\circ}$ vs. $45^{\circ}$ and $60^{\circ}$ & & & \multicolumn{2}{|c|}{0.001} \\
\hline Linear & 0.0000 & 0.0000 & $0^{\circ}$ vs. & \multicolumn{2}{|c|}{0.012} & \multicolumn{2}{|c|}{0.001} \\
\hline \multirow{3}{*}{$\begin{array}{l}\text { Treatment } \times \\
\alpha \text { linear }\end{array}$} & 0.6139 & 0.8025 & $0^{\circ}$ vs. $45^{\circ} \mathrm{N}$ & \multicolumn{2}{|c|}{0.018} & \multicolumn{2}{|c|}{0.084} \\
\hline & \multirow{3}{*}{0.0000} & \multirow{3}{*}{0.0206} & $0^{\circ}$ vs. $45^{\circ} \mathrm{S}$ & \multicolumn{2}{|c|}{0.022} & \multicolumn{2}{|c|}{0.000} \\
\hline & & & $0^{\circ}$ vs. $60^{\circ}$ & \multicolumn{2}{|c|}{0.000} & \multicolumn{2}{|c|}{0.009} \\
\hline \multirow{2}{*}{$\begin{array}{l}\text { Treatment } \times \\
\alpha \text { quadratic }\end{array}$} & & & $0^{\circ}$ vs. $60^{\circ} \mathrm{N}$ & \multirow{2}{*}{\multicolumn{2}{|c|}{$\begin{array}{l}0.000 \\
0.000\end{array}$}} & \multicolumn{2}{|c|}{0.024} \\
\hline & 0.0101 & 0.3156 & $0^{\circ}$ vs. $60^{\circ} \mathrm{S}$ & & & \multirow{2}{*}{\multicolumn{2}{|c|}{$\begin{array}{l}0.028 \\
0.416\end{array}$}} \\
\hline$R^{2}$ & 0.647 & 0.753 & $45^{\circ}$ vs. $60^{\circ}$ & \multicolumn{2}{|c|}{0.003} & & \\
\hline \multirow{4}{*}{\multicolumn{3}{|c|}{$\begin{array}{l}\alpha=\text { the absolute value of the angle, assuming the } \\
\text { horizontal projection of each trunk as reference axis. } \\
0^{\circ}=\text { trunk projection on the horizontal plane, } \\
180^{\circ}=\text { opposite side of the trunk projection. }\end{array}$}} & $45^{\circ} \mathrm{N}$ vs. $60^{\circ} \mathrm{N}$ & \multicolumn{2}{|c|}{0.014} & \multicolumn{2}{|c|}{0.670} \\
\hline & & & $45^{\circ} \mathrm{S}$ vs. $60^{\circ} \mathrm{S}$ & \multicolumn{2}{|c|}{0.062} & 0.1 & \\
\hline & & & $45^{\circ} \mathrm{N}$ vs. $45^{\circ} \mathrm{S}$ & 0.9 & & 0.0 & \\
\hline & & & $60^{\circ} \mathrm{N}$ vs. $60^{\circ} \mathrm{S}$ & 0.8 & & 0.92 & \\
\hline
\end{tabular}

the hormones caused by the inclination. In this context, promoters or specific inhibitors of root growth may play a significant role.

\section{Literature Cited}

Bargioni, G. 1993. Inclinazione del fusto dell'albero e disposizione delle radici nel terreno. L'Informatore Agrario 48:48-50.

Table 4. Effect of trunk inclination and ground slope on average root length of INRA GF 677 (Pru$n u s$ ) and apple ('Golden Delicious'/M.9) evaluated in the square grid $(0.5 \times 0.5 \mathrm{~m})$ corresponding to the barycentre defined by the regressions in the distance from the trunk and the absolute ( non sense? Neth. J. Agr. Sci. 31:335-348.

Dziljanov, L. 1965. The effect of the type of peach tree crown on its skeletal roots. Hort. Viticult. Sci., Sofia, 2:131-135.

Gautier, M. 1969. Comment raisonner la taille des arbres fruitiers à pépins. L' Arbor. Fruit. 179(1):20.

Klepper, B. 1991. Root-shoot relationships, p. 265286. In: Y. Waisel, A. Eshel, and U. Kafkafi (eds.). Plant roots: The hidden part. Marcel Dekker, New York.

Lambers, H. 1983. 'The functional equilibrium': Nibbling on the edges of a paradigm. Neth. J. Agr. Sci. 31:305-311.

Lockard, R.G. and G.W. Schneider. 1981. Stock and scion growth relationships and the dwarfing mechanism in apple. Hort. Rev. 3:315-375.

Nicotra, A. 1967. Apparati radicali di peschi morti per asfissia. Progresso Agricolo Bologna 9:907914.

Ponomarchuk, V.P. and I.S. Golovanov. 1973. The root system of apple trees with flat crowns (in Russian). Vestn. Sel'skokh. Nauki Kazakhstana 9:87-91. [English summary in Hort. Abstr. 44(6):333; 1974].

Russell, R.S. 1977. Plant root systems. McGrawHill, Maidenhead, U.K.

Trangmar, B.B., R.S. Yost, and G. Uehara. 1985. Application of geostatistics to spatial studies of soil properties. Adv. Agron. 38:45-94. 